EGU2020-1924

https://doi.org/10.5194/egusphere-egu2020-1924

EGU General Assembly 2020

(c) Author(s) 2020. This work is distributed under

the Creative Commons Attribution 4.0 License.

\title{
The rain-shadow effect for the Ethiopian Highlands
}

Bert Van Schaeybroeck ${ }^{1}$, Céline Van den Hende ${ }^{2}$, Jan Nyssen ${ }^{2}$, Sander Van Vooren², Michiel Van Ginderachter ${ }^{1}$, and Piet Termonia ${ }^{1,2}$

${ }^{1}$ Royal Meteorological Insititute of Belgium, Brussel, Belgium

${ }^{2}$ Ghent University, Ghent, Belgium

Recent work highlight the ambiguities in the definition and difficulties in quantification of the rain shadow effect. According to this phenomenon there is a reduced rainfall on the leeward side of the mountains as compared to the windward side. We present a statistical approach to study this effect in case climatological time series of model data are available in geographically complex regions. Our approach requires only gridded rainfall, wind and model elevation. We disentangle the aspects that contribute to the rainfall enhancement at the windward side. We apply the approach on the summer mountain precipitation (kerimt) over the Ethiopian Highlands based a new 21-year long climate run with the regional climate model ALARO-0 at a resolution of $4 \mathrm{~km}$. There is an overall increased rainfall of $20 \%$ for windward events as compared to leeward events, but locally this can exceed $150 \%$. This increase can be attributed to the positive differences between windward and leeward events in their frequency of occurrence, and, in the rainfall quantity during rainfall events. Differences in rainfall frequency, on the other hand, are spatially inhomogeneous and smaller than the spatial variations of the rainfall frequencies themselves. 